\title{
Avaliação de impactos de vizinhança utilizando matrizes numéricas
}

\author{
Neighborhood impact assessments using numerical \\ matrices
}

\section{Mário Antônio Ferreira Barreiros Alex Kenya Abiko}

\section{Resumo}

ste artigo trata do desenvolvimento de novos métodos para a elaboração e avaliação de estudos de impacto de vizinhança (EIVs). O trabalho apresenta um método que foi desenvolvido inicialmente de forma empírica, desde 2002, por meio do uso de matrizes de avaliação baseadas em critérios numéricos e que foram sendo aperfeiçoadas com o uso de novas metodologias, criadas a partir da matriz de Leopold (1971), pela adoção do método de abordagem sistêmica theory of systems approach definido por Churchman (1971) e de matrizes derivadas do método analytical hierachy process (AHP), propostas por Saaty (1991) para estudos de tomadas de decisões complexas. O método de utilização dessas matrizes foi utilizado em EIVs recentes, o que permitiu uma avaliação desse método. Os resultados indicam que o uso de matrizes numéricas pode contribuir para o aperfeiçoamento das avaliações de impactos de vizinhança.

Palavras-chaves: Estudo de impacto de vizinhança (EIV). Matrizes de avaliação. Matriz de Leopold. Enfoque sistêmico. Processo de análise hierárquica (AHP).

Mário Antonio Ferreira Barreiros Universidade de São Paulo São Paulo - SP - Brasil

Alex Kenya Abiko Universidade de São Paulo São Paulo - SP - Brasil

Recebido em 18/12/14 Aceito em 07/02/16

\section{Abstract}

The aim of this paper is to present the development of new methods for the preparation and evaluation of neighborhood impact studies (EIV), derived from Leopold's (1971) matrix. The method, which is presented in this paper, was developed through the use of evaluation matrices, empirically developed since 2002 by using Leopold's matrix (op. Cit.), the theory of systems approach, as defined by Churchman (1971) and, in addition, the analytic hierarchy process (AHP), created by Saaty (1991). The use of these matrices for the development of neighborhood impact assessment was applied in recent studies, allowing a review of the method and its utility. The results indicate that the use of numerical analysis can contribute to the improvement of neighborhood impact assessments.

Keywords: Neighborhood Impact Studies (EIV). Impact Assessment matrices. Leopold matrix. Systems approach. Analytical Hierarchy Process (AHP). 


\section{Introdução}

O EIV é um instrumento urbanístico introduzido pelo Estatuto da Cidade, Lei Federal n. 10.257 de 2001 (BRASIL, 2001), que visa contribuir com o processo de ordenação urbana dos municípios brasileiros. Deve ser requisitado pelos municípios brasileiros para a avaliação dos impactos decorrentes da implantação de empreendimentos, atividades ou equipamentos em ambiente urbano. A análise e aprovação do EIV deve preceder a aprovação de projetos com potencialidade de impactar sua vizinhança. Sua função primordial é, portanto, identificar e avaliar os impactos gerados no meio urbano e propor alternativas para minimizar ou mitigar os impactos negativos e propor medidas compensatórias para os casos em que a mitigação não for suficiente, podendo auxiliar tanto o poder público quanto o empreendedor nessas questões. Apesar de instituído em 2001, apenas recentemente o EIV vem sendo exigido como precondição para a aprovação de empreendimentos imobiliários.

Este trabalho apresenta inicialmente um cenário da aplicação do EIV na região metropolitana de São Paulo (RMSP) e, na sequência, trata do desenvolvimento de metodologia de avaliação de impactos de vizinhança baseada em matrizes numéricas. Tais matrizes foram desenvolvidas, inicialmente, de forma empírica e aperfeiçoadas com a prática de elaboração de EIVs realizados pelo autor com a adoção e adaptação de metodologias já utilizadas para a avaliação de impactos ambientais, como a matriz de Leopold (1971) e o método AHP.

Buscou-se neste trabalho:

(a) verificar o contexto brasileiro e a aplicação do instrumento EIV pelos municípios;

(b) verificar se os EIVs apresentados aos municípios possuíam algum tipo de avaliação de impactos baseada em matrizes numéricas; e

(c) demonstrar a aplicação de matrizes numéricas em EIVs desenvolvidos pelo autor e verificar sua utilidade.

\section{Materiais e Métodos}

As pesquisas foram subdivididas em quatro etapas distintas, descritas a seguir:

(a) pesquisas bibliográficas, nos principais repositórios acadêmicos, sobre o EIV, com o objetivo de obter um quadro atual sobre trabalhos existentes acerca do tema. Buscou-se verificar a publicação de estudos sobre a aplicação de matrizes numéricas em EIVs; (b) pesquisas nos municípios integrantes da região metropolitana de São Paulo (RMSP), com o objetivo de obter um quadro sobre a utilização do EIV como precondição para o licenciamento de projetos. Essa pesquisa, realizada com técnicos e secretários dos municípios, buscou dados sobre a existência de legislação específica que regulamenta o EIV, sua utilização como precondição para a aprovação de empreendimentos e sobre o conhecimento acerca de métodos de avaliação de impactos de vizinhança apoiados em matrizes numéricas;

(c) estudos de caso de EIVs executados e entregues em prefeituras para subsidiar o licenciamento de projetos. Essas pesquisas objetivaram a obtenção de um quadro sobre a utilização de matrizes numéricas como instrumento auxiliar de avaliação de impactos; e

(d) estudos de caso de EIVs desenvolvidos pelo autor, com o objetivo de demonstrar o desenvolvimento de matrizes numéricas e do método AHP como instrumento auxiliar de avaliação de impactos. Foram analisados dez EIVs desenvolvidos pelo autor em municípios paulistas.

Foram estudados EIVs desenvolvidos entre 2008 e 2014 a fim de demonstrar o método de avaliação por matrizes numéricas e o seu aperfeiçoamento. O desenvolvimento das matrizes foi promovido principalmente pela aplicação da matriz de Leopold (1971), da teoria do enfoque sistêmico ou systems approach (CHURCHMAN, 1971) e da aplicação do método de decisão baseado na análise hierárquica de processos, ou AHP, desenvolvido por Saaty (1991).

\section{Resultados}

\section{Etapa 1: pesquisas bibliográficas}

Nos últimos 50 anos o Brasil tem experimentado um rápido crescimento urbano, nem sempre acompanhado por processos adequados de planejamento e ordenamento de novos espaços das cidades, e passou de um país agrário da década de 1940, quando a população urbana era de $31,2 \%$, para um país eminentemente urbano a partir do período compreendido entre as décadas de 1960 e 1980, quando o território passa a ser integrado pelos transportes, pelas comunicações e pelo mercado (SANTOS, 2005). Atualmente as taxas de urbanização são bastante altas, e, de acordo com o Censo de 2010 (INSTITUTO..., 2012), o Estado de São Paulo apresentava um índice de 95,8\% de população urbana, em um universo de 41.262.199 habitantes. 
No Estado de São Paulo a regulação do uso do solo, visando à qualidade ambiental do meio urbano, passa a ter um marco importante no início do século $\mathrm{XX}$ com a publicação do Decreto $\mathrm{n}$. 2.141 de 14 de novembro de 1911, que instituiu o Código Sanitário. Embora de caráter eminentemente sanitarista, já apresentava um capítulo dedicado à regulação de habitações. Não havia nada diretamente relacionado com impactos no entorno.

A regulação do uso do solo na escala metropolitana inicia-se na década de 1970, relacionada com a proteção de mananciais e zoneamento industrial na região metropolitana de São Paulo. A questão dos mananciais passa a ser disciplinada legalmente pela Lei Estadual n. 898 de 18 de dezembro de 1975 (SÃO..., 1985). Em 17 de novembro de 1976 é publicada a Lei Estadual n. 1.172 (SÃO..., 1985), que estabeleceu normas de restrição do uso e ocupação do solo para as áreas inseridas nos limites definidos pela Lei n. 898/1975 (SÃO..., 1985). O zoneamento industrial estabelecido pela Lei n. 1817/1976 (SÃO..., 1985) definiu as zonas de uso predominantemente industriais (Zupis) na região metropolitana de São Paulo e passou a regular o uso do solo dessas áreas.

No âmbito nacional, apenas no final da década de 1970 é que passam a existir instrumentos direcionados para a melhoria da qualidade do ambiente urbano através do parcelamento do solo urbano. Em 19 de dezembro de 1979 é publicada a Lei Federal n. 6.766 (BRASIL, 1985), que passou a disciplinar o parcelamento do solo urbano, substituindo o Decreto-Lei n. 58, de 10 de dezembro de 1931. A regulação da produção de espaços urbanizados se torna específica em relação às condições ambientais, não permitindo o parcelamento do solo em locais onde as condições fossem ambientalmente desfavoráveis, além de instituir os requisitos urbanísticos mínimos para loteamentos. A questão dos impactos ainda é tratada de forma indireta, por meio de medidas restritivas de uso e ocupação do solo.

Em 31 de agosto de 1981 a Lei Federal n. 6.938, de 31 de agosto de 1981 (BRASIL, 1981), institui a Política Nacional do Meio Ambiente e cria o Conselho Nacional do Meio Ambiente (Conama). Em 23 de janeiro de 1986 esse conselho publica a Resolução Conama n. 001/1986 (CONSELHO..., 1986), que se tornou a primeira regulação voltada para a avaliação dos impactos ambientais. A Resolução Conama n. 001/1986 passa a tornar obrigatória a apresentação de estudo de impacto ambiental e relatório de impacto no meio ambiente (EIA-Rima), para projetos urbanísticos acima de 100 hectares ou em áreas consideradas de relevante interesse ambiental, assim definidas por órgãos federais, estaduais ou municipais. Dessa forma, tem início o desenvolvimento de estudos de impacto ambiental no Brasil.

Com relação ao processo do desenvolvimento dos EIVs como instrumento urbanístico, Moreira (1997, p. 21-24) informa que desde 1971 o Plano Diretor de Desenvolvimento Integrado do Município de São Paulo já demonstrava preocupação com a qualidade do ambiente urbano. Em 1972 a Lei Municipal n. 7805 de $1^{\circ}$ de novembro de 1972 (SÃO..., 1990), artigo 26, considerava o impacto dos grandes empreendimentos sobre o tráfego, exigindo dispositivos para entrada e saída de veículos para minimizar a interferência do empreendimento no tráfego da via de acesso ao imóvel. O citado autor continua informando que em 1988 a Lei Municipal n. 10.506, de 4 de maio de 1988 (SÃO..., 1988), passou a transferir as despesas de obras e serviços relacionados com o melhoramento das operações do sistema viário para os empreendimentos particulares. Esse é o primeiro movimento relacionado com a obrigatoriedade de medidas mitigatórias para os impactos decorrentes da implantação de empreendimentos imobiliários. O autor informa ainda que em 4 de abril de 1990 é promulgada a Lei Orgânica do Município de São Paulo (SÃO..., 1990), que passa a requerer a apresentação do relatório de impacto de vizinhança para os empreendimentos com significativa repercussão ambiental e na infraestrutura, como vemos no texto da lei:

Artigo 159 - Os projetos de implantação de obras ou equipamentos, de iniciativa pública ou privada, que tenham, nos termos da lei, significativa repercussão ambiental ou na infra-estrutura urbana, deverão vir acompanhados de relatório de impacto de vizinhança.

Parágrafo 1 - Cópia do relatório de impacto de vizinhança será fornecida gratuitamente, quando solicitada, aos moradores da área afetada e suas associações.

Parágrafo 2 - Fica assegurado ao órgão público competente a realização de audiência pública, antes da decisão final sobre o projeto, sempre que requerida, na forma da lei, pelos moradores e associações mencionadas no parágrafo anterior.

O artigo 159 da Lei Orgânica (SÃO..., 1992) foi regulamentado por meio da Lei n. 11.228 , de 26 de Junho de 1992 - Código de Obras e Edificações, e pelo Decreto n. 32.329, de 23 de Setembro de 
1992, que regulamentou o Código de Obras e Edificações. Além disso, a Lei n. 11.228 (SÃO..., 1992), em seu Anexo 1, item 5, determina que:

A execução de obras, incluindo os serviços preparatórios e complementares, suas instalações e equipamentos, será procedida de forma a obedecer ao projeto aprovado, à boa técnica, à NTOP e ao direito de vizinhança, a fim de garantir a segurança dos trabalhadores, da comunidade, das propriedades e dos logradouros públicos, observada em especial a legislação trabalhista pertinente.

Não obstante, a questão dos impactos urbanos derivados da expansão urbana e da construção de novos empreendimentos imobiliários permaneceu sem regulamentação específica, até dezembro de 2001, restrita às leis de uso e ocupação do solo, exceto nos casos de impactos no tráfego, gerados por empreendimentos caracterizados como polos geradores de tráfego, cuja conceituação e regulação no Estado de São Paulo inicia-se em 1979, com a publicação do Decreto Municipal n. 15.980/1979 - Município de São Paulo (PEREIRA, 2011).

Somente em dezembro de 2001, com a Lei Federal n. 10.257 (BRASIL, 2001), denominada Estatuto da Cidade, é que se cria um instrumento legal para a avaliação de impactos especificamente urbanos, que estabelece a análise dos seguintes itens:

(a) adensamento populacional;

(b) equipamentos urbanos e comunitários;

(c) uso e ocupação do solo;

(d) valorização imobiliária;

(e) geração de tráfego e demanda por transporte público;

(f) ventilação e iluminação; e

(g) paisagem urbana e patrimônio natural e cultural.

Esse é o programa mínimo definido pela lei federal, cabendo aos municípios, através de legislação específica, ampliar esse programa na defesa de seus interesses para garantir o ordenamento espacial, de acordo com critérios estabelecidos como necessários para o licenciamento de empreendimentos e atividades em seu território.

A regulamentação do EIV pelos municípios vem sendo feita de forma lenta, mas gradual, com um número crescente de municípios requerendo a apresentação desse tipo de estudo como precondição para a aprovação de empreendimentos imobiliários, em que pese municípios como São
Paulo já terem manifestado preocupações com os impactos urbanos desde a década de 1970 (ALMEIDA; BRUNA; SIMÕES JUNIOR, 2004).

Apesar de estar cada vez mais presente nos municípios brasileiros, o EIV ainda é um instrumento que deve ser aprimorado para cumprir seu papel efetivo no ordenamento dos espaços urbanos. Um dos pontos a serem desenvolvidos é o relacionado com a metodologia de avaliação de impactos que deve ser aprimorada (MOREIRA, 1997; LOLLO; RÖHM, 2006). Pouca atenção tem sido dada ao processo e sistema de elaboração e à metodologia de avaliação e análise de impactos de vizinhança.

Marques (2010) reforça essa constatação em sua dissertação que envolveu a pesquisa direta sobre 19 EIVs realizados no Distrito Federal. A autora afirma que a maioria dos relatórios são superficiais, pouco objetivos, assemelhando-se a um roteiro de recomendações (MARQUES, 2010, p. 114). A subjetividade, tanto na avaliação de impactos quanto na análise dos EIVs, leva a distorções sobre a avaliação dos impactos produzidos pela implantação de novos empreendimentos. Esse é um fato corroborado por Lollo e Röhm (2005, 2006) que apontam duas categorias de aspectos negligenciados nos EIVs: 1) deficiências provenientes da legislação e 2) deficiências decorrentes da forma de condução dos trabalhos.

As pesquisas sobre os impactos de vizinhança ainda são incipientes no Brasil. A produção de literatura acadêmica sobre esse instrumento ainda é escassa. Os principais pesquisadores que se dedicam à compreensão e ao aprofundamento dos estudos sobre o tema são Moreira (1997), que analisou 27 casos de relatórios de impacto de vizinhança, Cymbalista (2001), Mota e Aquino (2002), De Campos (2005), , Lollo e Röhm (2005, 2006), Rocco (2006), além de pesquisadores como Chamié (2010), Marques (2010), Molina Jr. (2011), Abiko e Barreiros (2014), entre outros. Dos artigos pesquisados, apenas Mota e Aquino (2002), Lollo e Röhm (2005) e Molina Jr. (2011) fazem referência ao uso de matrizes para avaliação de impactos de vizinhança.

Não foi encontrada na pesquisa bibliográfica nenhuma referência ao uso de matrizes numéricas no desenvolvimento de EIV, embora a utilização de tais matrizes seja bastante comum nos estudos de impactos ambientais (EIA), como comprovam os trabalhos de Glasson et al. (1999, p. 112) e Shepard (2005, p. 41). O uso de matrizes também é relatado por Canter et al. (1996) como um dos métodos mais abrangentes de avaliação de impactos ambientais. 
Lawrence (2007a, 2007b) aprofunda as pesquisas sobre a avaliação da significância de impactos em EIA definindo três enfoques de avaliação: o enfoque técnico (technical approach), o enfoque colaborativo (collaborative approach) e o enfoque fundamentado (reasoned approach).

\section{Etapa 2: o panorama da utilização do EIV na região metropolitana de São Paulo}

Para obter uma amostra da utilização do EIV como instrumento urbanístico, buscou-se compreender seu alcance de utilização na região metropolitana de São Paulo (RMSP), a mais importante e populosa região metropolitana do Brasil (EMPRESA..., 2015). Por agregar 39 municípios, a região possibilita verificar a disseminação da utilização do instrumento.

Para essa etapa foram realizadas entrevistas com secretários e técnicos de todos os 39 municípios da RMSP. As entrevistas foram feitas mediante contato direto nas prefeituras, com entrevistas presenciais nas secretarias com atribuições relacionadas com o EIV. Foram feitas apenas três perguntas:

(a) o município requer a elaboração de EIV como precondição de aprovação de empreendimentos conforme determina o Estatuto da Cidade?

(b) o município possui legislação específica para regulamentar a requisição do EIV?

(c) o município já recebeu algum EIV cujas avaliações de impacto fossem apoiadas por matrizes numéricas?

Com as respostas foi montado um quadro síntese que retrata a existência de legislação municipal específica para a aplicação do EIV e sobre sua efetiva requisição para novos empreendimentos. Os resultados das pesquisas foram tabulados e estão apresentados na Tabela 1 deste trabalho.

A pesquisa na RMSP demonstrou que apenas 11 dos 39 municípios possuem legislação regulamentando o EIV, e que 1 município requer o estudo de forma esporádica mesmo sem legislação específica, como demonstra a Tabela 1. Vale lembrar que cada município atua de maneira autônoma. Rocco (2006, p. 42) esclarece que a elaboração do EIV é uma atribuição privativa do município e exclui a possibilidade de que esses estudos sejam exigidos por órgãos estaduais ou federais. As análises municipais, dentro dos municípios estudados, são feitas tendo como base o conhecimento acumulado dos técnicos, sem o auxílio de um sistema ou método de análise, com algumas exceções como a do município de Embu das Artes, que possui uma matriz simples de identificação de impactos. Não foi constatado na RMSP nenhum município, dentre os 39 que compõem a região, que apoie suas análises em critérios matemáticos, ou seja, relacionados com avaliações numéricas, que se utilizam de operações matemáticas que permitam estabelecer critérios de relações de grandeza entre os impactos.

\section{Etapa 3: a utilização de matrizes numéricas para avaliação de impactos de vizinhança}

Nessa etapa o objetivo era o de verificar a existência de métodos de avaliação de impactos baseados em matrizes numéricas na atual produção de EIV.

Para obter uma amostra de seu uso atual foram realizadas pesquisas em 2 municípios de médio porte: Santo André e Jundiaí. Tais municípios foram escolhidos por disponibilizarem os EIVs na internet.

Pesquisas em outros municípios foram prejudicadas pelas dificuldades no acesso aos processos de análise de EIV. Também não houve acesso a estudos desenvolvidos por escritórios de urbanismo por motivos relacionados com o sigilo sobre os trabalhos desenvolvidos.

Foram coletados 12 EIVs desenvolvidos por 12 autores diferentes. Embora seja um universo pequeno de pesquisa, a intenção era a de confirmar o que já se observava, de forma ainda não sistematizada, nas entrevistas realizadas para a etapa 2, em que os técnicos informaram acerca da inexistência de avaliações numéricas nos EIV apresentados. Os EIVs analisados foram obtidos por meio de sua publicação na internet e estão descritos no apêndice deste artigo.

A análise de 12 EIVs produzidos por 12 diferentes escritórios de urbanismo confirmou as informações de técnicos municipais entrevistados na etapa 2 , que afirmavam não ter conhecimento de avaliações de impactos de vizinhança baseadas em matrizes numéricas. A Tabela 2 demonstra o resultado das pesquisas. Os endereços de acesso (links) para esses trabalhos encontram-se no apêndice deste trabalho. 
Tabela 1 - Municípios da RMSP que requisitam o EIV, que possuem legislação específica e que já utilizaram matrizes numéricas em EIV

\begin{tabular}{|c|c|c|c|c|c|c|}
\hline & \multirow[b]{2}{*}{ Município } & \multirow[t]{2}{*}{ Requisita o EIV } & \multicolumn{2}{|c|}{ Possui Lei Específica para EIV } & \multicolumn{2}{|c|}{ Uso de Matriz Numérica } \\
\hline & & & Sim & Não & Sim & Não \\
\hline 1 & Arujá & $x$ & & $\mathrm{x}$ & & $\mathrm{x}$ \\
\hline 2 & Barueri & $x$ & $x$ & & & $x$ \\
\hline 3 & Biritiba Mirim & & & $\mathrm{x}$ & & \\
\hline 4 & Caieiras & $\mathrm{x}$ & $x$ & & & $x$ \\
\hline 5 & Cajamar & & & $\mathrm{x}$ & & \\
\hline 6 & Carapicuiba & & & $x$ & & \\
\hline 7 & Cotia & $x$ & & $x$ & & $x$ \\
\hline 8 & Diadema & $\mathrm{x}$ & $x$ & & & $x$ \\
\hline 9 & Embu das Artes & $x$ & $\mathrm{x}$ & & & $x$ \\
\hline 10 & Embú-Guaçu & & & $\mathrm{x}$ & & \\
\hline 11 & Ferraz de Vasconcelos & & & $x$ & & \\
\hline 12 & Francisco Morato & & & $x$ & & \\
\hline 13 & Franco da Rocha & & & $\mathrm{x}$ & & \\
\hline 14 & Guararema & & & $\mathrm{x}$ & & \\
\hline 15 & Guarulhos & $\mathrm{x}$ & $x$ & & & $\mathrm{x}$ \\
\hline 16 & Itapecerica da Serra & & & $x$ & & \\
\hline 17 & Itapevi & & & $x$ & & \\
\hline 18 & Itaquaquetuba & & & $x$ & & \\
\hline 19 & Jandira & & & $x$ & & \\
\hline 20 & Juquitiba & & & $x$ & & \\
\hline 21 & Mairiporã & & & $\mathrm{x}$ & & \\
\hline 22 & Mauá & $x$ & $x$ & & & $x$ \\
\hline 23 & Mogi das Cruzes & & & $x$ & & \\
\hline 24 & Osasco & & & $\mathrm{x}$ & & \\
\hline 25 & Pirapora do Bom Jesus & & & $x$ & & \\
\hline 26 & Poá & & & $x$ & & \\
\hline 27 & Ribeirão Pires & & & $x$ & & \\
\hline 28 & Rio Grande da Serra & & & $\mathrm{x}$ & & \\
\hline 29 & Salesópolis & & & $x$ & & \\
\hline 30 & Santa Isabel & & & $x$ & & \\
\hline 31 & Santana de Parnaiba & & & $\mathrm{x}$ & & \\
\hline 32 & Santo André & $x$ & $x$ & & & $x$ \\
\hline 33 & São Bernardo & $\mathrm{x}$ & $x$ & & & $x$ \\
\hline 34 & São Caetano & $x$ & $x$ & & & $x$ \\
\hline 35 & São Lourenço da Serra & & & & & \\
\hline 36 & São Paulo & $x$ & $x$ & & & $x$ \\
\hline 37 & Suzano & & & & & \\
\hline 38 & Taboão da Serra & & & & & \\
\hline 39 & Vargem Grande & $x$ & $x$ & & & $x$ \\
\hline
\end{tabular}

Nota: O Município de São Paulo possui legislação específica, anterior à edição do Estatuto da Cidade (EC). Portanto, não há regulamentação específica para EIV nos termos do EC.

Tabela 2 - Utilização de matrizes numéricas em EIV

\begin{tabular}{|r|l|l|l|c|}
\hline \multicolumn{5}{|c|}{ Análise de EIV - verificação de uso de matrizes numéricas } \\
\hline n.o & Empreendimento & Município & Autor & Uso de matrizes numéricas \\
\hline 1 & Edifício residencial & Santo André & Escritório A & Não \\
\hline 2 & Sorveteria & Santo André & Escritório B & Não \\
\hline 3 & Edifício comercial & Santo André & Escritório C & Não \\
\hline 4 & Campus universitário & Santo André & Escritório D & Não \\
\hline 5 & Conj Habitacional HIS & Santo André & Escritório E & Não \\
\hline 6 & Edifício comercial & Santo André & Escritório F & Não \\
\hline 7 & Comércio de madeiras & Jundiaí & Escritório G & Não \\
\hline 8 & Posto de combustível & Jundiaí & Escritório H & Não \\
\hline 9 & Edifício comercial & Jundiaí & Escritório I & Não \\
\hline 10 & Galpão comercial & Jundiaí & Escritório J & Não \\
\hline 11 & Edifício misto & Jundiaí & Escritório K & Não \\
\hline 12 & Supermercado & Jundiaí & Escritório L & Não \\
\hline
\end{tabular}

28 Barreiros, M. A. F.; Abiko, A. K. 


\section{Etapa 4: desenvolvimento das matrizes}

A quarta etapa das pesquisas relaciona-se com o desenvolvimento e a aplicação de matrizes numéricas para a avaliação de impactos de vizinhança. As bases desta pesquisa foram as matrizes numéricas desenvolvidas em nossas pesquisas, inicialmente de forma empírica, que foram, com a acumulação de conhecimento prático e acadêmico, sendo aperfeiçoadas com o auxílio de matrizes de avaliação conforme proposto por Leopold (1971), com a utilização do conceito de enfoque sistêmico, desenvolvido por Churchman (1971) e com a utilização do método AHP criado e desenvolvido por Saaty (1991).

A utilização de matrizes para avaliação de impactos de vizinhança ainda é incipiente. Apesar de Lollo e Röhm (2006) já proporem a análise de impactos de vizinhança com a utilização de uma matriz inspirada na matriz de Leopold, ainda são poucos os EIVs que se utilizam dessa ferramenta. Verificou-se, nas pesquisas realizadas para este trabalho, que os estudos de impacto não apresentam metodologias de avaliação baseadas em critérios matemáticos. Corroborando com nossas pesquisas, Moreira (1997) apresenta em sua tese 27 casos de relatórios de impacto de vizinhança, em que em nenhum caso se verifica a existência de metodologia de avaliação baseada em critérios matemáticos. Ressalta-se, porém, que o uso de matrizes simples, não numéricas, já está sendo requisitado por alguns municípios, como Jundiaí e Embu das Artes.

\section{O desenvolvimento empírico de uma metodologia com a utilização de matrizes numéricas}

A experiência empírica foi fundamentada em 40 estudos de impacto de vizinhança, desenvolvidos durante o período de 2008 a 2014, em municípios paulistas. Em todos eles foram utilizadas matrizes numéricas como método de avaliação. As primeiras matrizes foram baseadas inicialmente na lógica booleana, em que eram utilizadas apenas as variáveis $+1,0$ e -1 , e o valor -1 era usado no caso da avaliação de um item tido como negativamente impactante para a vizinhança, o valor 0 era usado para os casos em que os impactos eram considerados nulos e o valor +1 utilizado para pontuar os itens considerados como de impacto positivo. Os impactos foram classificados como positivos, negativos e nulos. Os impactos positivos e os negativos eram, por sua vez, reclassificados por sua severidade, reversibilidade, alcance espacial, alcance temporal, contínuo, sazonal ou intermitente e quanto à possibilidade de remediação ou mitigação.

A matriz avaliava um total de 51 itens, divididos em 8 grandes temas: infraestrutura; estrutura viária; paisagem; ambiente natural, histórico e morfológico; produção de poluição; equipamentos urbanos e comunitários; uso e ocupação do solo; e estrutura econômica.

A matriz resumo pontuava os impactos como se vê na Tabela 3.

A partir de 2013, com o desenvolvimento de pesquisas acadêmicas voltadas para métodos de avaliação de impactos ambientais, foi introduzida uma primeira adaptação da matriz de Leopold para avaliação de impactos de vizinhança. Esse novo instrumento de avaliação foi a matriz de magnitude e importância de impactos de vizinhança, apresentada na Tabela 4. Essa matriz se baseou na matriz proposta por Leopold (1971), que desenvolveu uma matriz avaliando de forma numérica as relações entre a magnitude do impacto sobre a importância do tema avaliado.

A matriz de Leopold trouxe um grande avanço nas metodologias de avaliação de impactos. Ela porém não incorpora os processos de inter-relação entre os impactos que poderiam ser avaliados. Essa relação entre os itens geradores de impactos entre si e a relação deles com um ambiente urbano dinâmico não são avaliadas na matriz de Leopold. As pesquisas levaram ao entendimento de que uma forma de enfrentar essa problemática é fornecida pelo enfoque sistêmico (systems approach), proposto por Churchman (1971).

A compreensão de que os fatores impactantes de um empreendimento devam ser avaliados considerando as dinâmicas de causa e efeito decorrentes das inter-relações entre os impactos, e entre eles e o meio em que se inserem, passou a ser necessária.

A adoção do enfoque sistêmico permitiu:

(a) a compreensão da complexidade das interrelações entre os impactos;

(b) a compreensão de que o todo é maior que a soma das partes, isto é, a mensuração de impactos deve levar em conta uma abordagem "interrelacional" dos impactos e uma avaliação final baseada em subíndices, que compreendam as interrelações entre as partes, entre si e entre elas e o todo, o que inclui a dimensão temporal, os efeitos cumulativos e os efeitos potencializadores de impactos; e

(c) a abordagem multidisciplinar das análises. 
Tabela 3 - Exemplo parcial da matriz de 2008, com as atribuições de valores para impactos, negativos e nulos

\begin{tabular}{|c|c|c|c|c|c|c|c|c|c|}
\hline \multirow[t]{2}{*}{ Matriz de Impactos } & \multirow{3}{*}{ CLASSIFICAÇÃO } & \multirow[b]{2}{*}{ Índice } & \multirow[b]{2}{*}{ TIPO DE IMPACTO } & \multirow[b]{2}{*}{ SEVERIDADE } & \multirow[b]{2}{*}{ REVERSIBILIDADE } & \multirow[b]{2}{*}{ ESPECTRO } & & & \\
\hline & & & & & & & AMPL.TEMP. & DURAÇÂO & REMEDIAÇÂO \\
\hline INFRA-ESTRUTURA URBANA & & & & & & & & & \\
\hline Abastecimento de água & Nulo & 0 & & & & & & & \\
\hline 2 Esgotamento sanitário & Negativo & -1 & Significativo & Média & Sim & Amplo & Médio & Contínuo & Sim \\
\hline Drenagem urbana & Negativo & -1 & Significativo & Baixa & Sim & Restrito & Curto & Intermitente & Sim \\
\hline $4 \sqrt{\text { Iluminação pública }}$ & Nulo & 0 & & & & & & & \\
\hline Indice do sub-tema & Negativo Médio & $-0,50$ & & & & & & & Sim \\
\hline ESTRUTURA VIÁRIA URBANA & & & & & & & & & \\
\hline$5 \longdiv { \text { Alterações do sistema } }$ & Nulo & 0 & & & & & & & \\
\hline 6 Geração de trá́ego & Negativo & -1 & Significativo & Baixa & Não & Local & Longo & Intermitente & Sim \\
\hline 7 Incremento período de obras & Negativo & -1 & Não Significativo & Média & Sim & Amplo & Curto & Intermitente & Sim \\
\hline Indice do sub-tema & Negativo Médio & $-0,67$ & Significativo & & & & & & Sim \\
\hline PAISAGEM URBANA & & & & & & & & & \\
\hline 8 Alteração da paisagem & Nulo & 0 & & & & & & & \\
\hline 9 Alteração do padrão urbanístico & Nulo & 0 & & & & & & & \\
\hline Barreiras visuais & Nulo & 0 & & & & & & & \\
\hline Paisagismo & Positivo & 1 & Significativo & Baixa & Não & Local & Longo & Contínuo & \\
\hline Ventilação - alterações e barreiras & Nulo & 0 & & & & & & & \\
\hline Insolação - sombreamento de edificações e espaços & Nulo & 0 & & & & & & & \\
\hline Indice do sub-tema & Positivo Baixo & 0,2 & Significativo & & & & & & \\
\hline AMBIENTE NATURAL HISTÓRICO MORFOLÓGICO & & & & & & & & & \\
\hline Alteração ambiente natural & Negativo & -1 & Não Significativo & Baixa & Não & Restrito & Longo & Contínuo & Não \\
\hline Interferência ambiente histórico & Nulo & 0 & & & & & & & \\
\hline Alteração da morfologia terreno & Nulo & 0 & & & & & & & \\
\hline Indice do sub-tema & Negativo Baixo & $-0,33$ & & & & & & & Não \\
\hline PRODUÇÃO DE POLUIÇÃO & & & & & & & & & \\
\hline \begin{tabular}{|l|} 
Poluição atmosférica \\
\end{tabular} & & 0 & & & & & & & \\
\hline Poluição por Resíduos Sólidos & & -1 & Significativo & Média & Sim & Amplo & Curto & Contínuo & Sim \\
\hline \begin{tabular}{|l|} 
Poluição em corpos d'água \\
\end{tabular} & & 0 & & & & & & & \\
\hline Poluição visual & & 0 & & & & & & & \\
\hline Poluição sonora & & 0 & & & & & & & \\
\hline Poluição por odores & & 0 & & & & & & & \\
\hline Vibrações e tremores por máquinas e assemelhados & & 0 & & & & & & & \\
\hline Indice do sub-tema & Negativo Baixo & $-0,17$ & & & & & & & Sim \\
\hline EQUIPAMENTOS URBANOS E COMUNITÁRIOS & & & & & & & & & \\
\hline URBANOS INFRA-ESTRUTURA & & & & & & & & & \\
\hline Equipamentos para abastecimento de água & Nulo & 0 & & & & & & & \\
\hline Equipamentos para tratamento de água & Nulo & 0 & & & & & & & \\
\hline Equipamentos para recolhimento de esgotos & Nulo & 0 & & & & & & & \\
\hline Equipamentos para tratamento de esgotos & Negativo & -1 & Transitório & Baixa & Sim & Restrito & Curto & Contínuo & Sim \\
\hline Equipamentos para energia elétrica & Nulo & 0 & & & & & & & \\
\hline \begin{tabular}{|l|} 
Equipamentos para drenagem \\
\end{tabular} & Negativo & -1 & Transitório & Baixa & Sim & Restrito & Curto & Contínuo & Sim \\
\hline Equipamentos para telecomunicações & Nulo & 0 & & & & & & & \\
\hline Indice do sub-tema & Negativo Baixo & $-0,29$ & & & & & & & Sim \\
\hline \begin{tabular}{|l|} 
URBANOS TRANSPORTE \\
\end{tabular} & & & & & & & & & \\
\hline Incremento de demanda/carregamento & Positivo & 1 & Permanente & & & Restrito & Longo & & \\
\hline Necessidade de investimentos & Negativo & -1 & Transitório & Baixa & Sim & Amplo & Longo & & Sim \\
\hline Equipamentos (ponto e onibus) & Negativo & -1 & Permanente & Baixa & Sim & Restrito & Curto & & Sim \\
\hline Modificação de sistema & Nulo & 0 & & & & & & & \\
\hline Indice do sub-tema & Negativo Baixo & $-0,25$ & & & & & & & Sim \\
\hline EQUIPAMENTOS SOCIAIS & & & & & & & & & \\
\hline Escolas - creches - fundamental - & Negativo & -1 & Permanente & Baixa & Sim & Restrito & Médio & & Sim \\
\hline Escolas - especiais - superior & Nulo & 0 & & & & & & & \\
\hline Postos de Saúde & Nulo & 0 & & & & & & & \\
\hline Postos de Segurança & Negativo & -1 & Permanente & Baixa & Sim & Restrito & Médio & & Sim \\
\hline Seriços de apoio social & Nulo & 0 & & & & & & & \\
\hline Indice do sub-tema & Negativo Baixo & $-0,4$ & & & & & & & Sim \\
\hline USO E OCUPAÇÃO DO SOLO & & & & & & & & & \\
\hline Alteração de uso & Nulo & 0 & & & & & & & \\
\hline Tipologia da ocupação & Nulo & 0 & & & & & & & \\
\hline Indices Urbanísticos T0 e CA & Nulo & 0 & & & & & & & \\
\hline Taxa de permeabiliade do terreno & Nulo & 0 & & & & & & & \\
\hline Usos perigosos para saúde & Nulo & 0 & & & & & & & \\
\hline Usos incomodos ou desconformes & Nulo & 0 & & & & & & & \\
\hline Valorização imobiliária & Positivo & 1 & Permanente & & & & & & \\
\hline Conformidade com legislação & Positivo & 1 & Permanente & & & & & & \\
\hline Indice do sub-tema & Positivo Baixo & 0,25 & & & & & & & \\
\hline ESTRUTURA SÓCIO-ECONOMICA & & & & & & & & & \\
\hline \begin{tabular}{|l|} 
Alteração do padrão social do entorno \\
\end{tabular} & Nulo & 0 & & & & & & & \\
\hline Inserção de desnivelamento social & Nulo & 0 & & & & & & & \\
\hline 0 Incremento da economia local & Positivo & 1 & Permanente & & & & & & \\
\hline Criação de empregos & Positivo & 1 & Permanente & & & & & & \\
\hline Indice do sub-tema & Positivo Médio & 0,5 & & & & & & & \\
\hline
\end{tabular}

Fonte: EIV de empreendimento residencial, desenvolvido pelo autor em 2008. 
Tabela 4 - Exemplo parcial da matriz de magnitude e importância

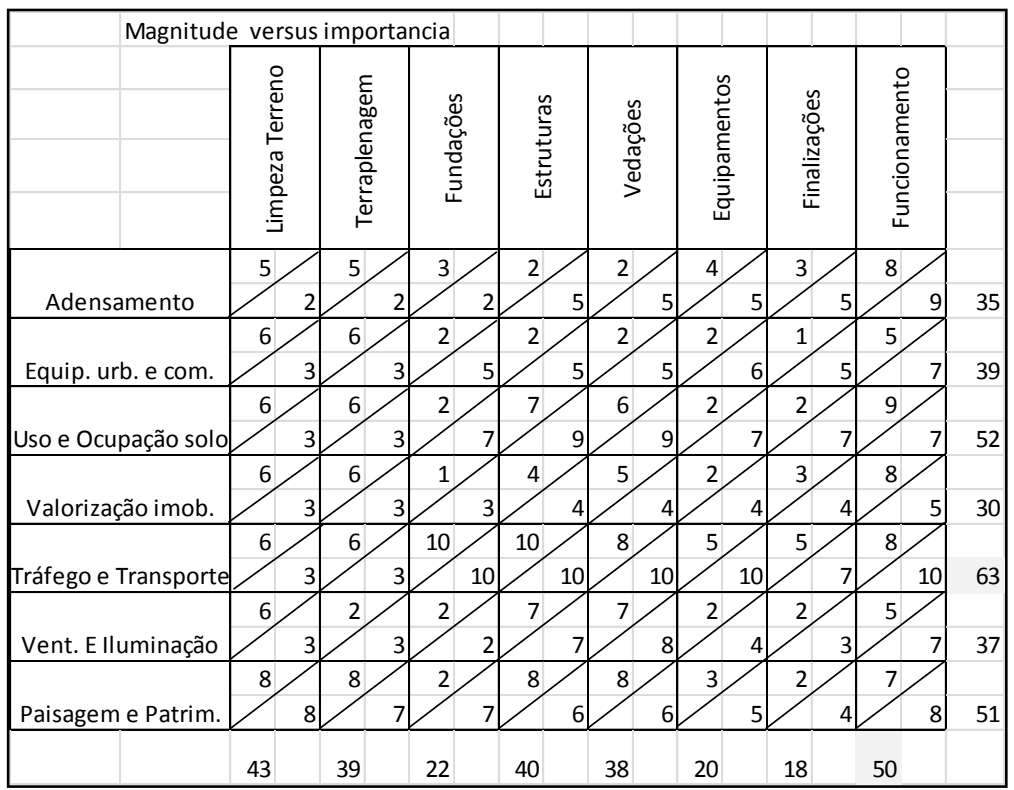

Fonte: EIV de um hospital, desenvolvido pelo autor em 2013.

Churchman (1971, p. 51) cita cinco considerações básicas do enfoque sistêmico:

(a) os objetivos totais do sistema e, mais especificamente, as medidas de rendimento do sistema inteiro;

(b) o ambiente do sistema: as restrições fixas;

(c) os recursos do sistema;

(d) os componentes do sistema, suas atividades, finalidades e medidas de rendimento; e

(e) a administração do sistema.

No enfoque sistêmico, os EIVs devem levar em consideração o sistema urbano e sua complexidade de componentes e inter-relações, identificando e avaliando os impactos dentro de uma abordagem que equacione esses cinco elementos.

Segundo Bertalanffy (1977, p. 25), “[...] a análise dos sistemas trata a organização como um sistema de variáveis mutuamente dependentes [...]". Para atingir tal propósito é necessário compreender o sistema e suas variáveis. No caso dos EIVs o sistema a ser compreendido é o sistema urbano e suas dinâmicas e as variáveis que se alteram conforme são impactadas. Além disso, é preciso que nos EIVs sejam definidos claramente os objetivos gerais e específicos do estudo, o ambiente urbano com sua complexidade de dinâmicas, os recursos à disposição dos estudos, a gama completa dos componentes do estudo incluindo medidas de rendimento vinculadas com impactos e o monitoramento dos impactos.

Churchman (1971, p. 27-28) afirma que,
[...] os sistemas são constituídos de conjuntos de componentes que atuam juntos na execução do objetivo global do todo. $O$ enfoque sistêmico é simplesmente um modo de pensar a respeito desses sistemas totais e seus componentes [...].

No mesmo sentido, Bertalanffy (1971, p. 84) esclarece que é preciso compreender que,

[...] um sistema pode ser definido como um complexo de elementos em interação. A interação significa que os elementos $P$ estão em relações $R$, de modo que o comportamento de um elemento $P$ em $R$ é diferente de seu comportamento em outra relação $R[\ldots]$.

Entende-se que tais conceitos deveriam ser aplicados nos estudos de impacto de vizinhança que produzem análises mais consistentes, complexas e aprofundadas sobre os impactos. Isso se refletiu na metodologia de avaliação de impactos. Cada um dos elementos analisados passou a ser compreendido como um subsistema. O mesmo ocorreu com a compreensão das dimensões de alcance dos impactos nas dimensões espaciais e temporais.

A abrangência espacial e temporal é essencial na compreensão dos impactos, pois cada elemento de análise do sistema possui uma característica específica com relação ao seu alcance espacial e temporal. Além disso, no enfoque sistêmico as inter-relações entre os elementos do sistema afetam e modificam tais características. 
$\mathrm{Na}$ análise do alcance espacial de impactos, nossa metodologia sugere a análise e a caracterização de quatro esferas de alcance:

(a) os impactos cujo alcance fique restrito ao terreno do empreendimento;

(b) os impactos cujo alcance atinja a vizinhança imediata, ou a área de vizinhança imediata (AVI), composta pelos vizinhos que possuam divisas comuns e os que estejam localizados no lado oposto das vias que delimitem o empreendimento;

(c) os impactos cujo alcance atinja a área de influencia direta (AID), que corresponde às quadras que envolvem a quadra de localização do empreendimento e que, em alguns estudos analisados, corresponde a uma área inserida dentro de um círculo com raio de $500 \mathrm{~m}$, que seria a área de alcance normal de um pedestre para realização de atividades urbanas - trabalho, educação, recreação, compras, etc; e

(d) os impactos cujo alcance atinja as áreas de influência indireta (AII), que corresponde ao recorte espacial que ultrapassam a AID e que variam em função das características de cada impacto.

Importante ressaltar que as AID e as AII se caracterizam como recortes espaciais utilizados unicamente para a análise dos impactos, não correspondendo diretamente ao alcance dos impactos. $\mathrm{O}$ alcance dos impactos está relacionado com o tipo de empreendimento ou atividade, o seu porte, a magnitude do impacto e o meio pelo qual se propaga. $\mathrm{O}$ alcance de impactos diretos e indiretos depende intrinsecamente de uma avaliação sistêmica relacionando as características do empreendimento/atividade com as características de seus meios de inserção, que correspondem aos meios físico, biótico e socioeconômico.

Os impactos de alguns componentes do sistema empreendimento, como água e esgoto, implicam em uma abrangência espacial que inclua as áreas de produção, tratamento e distribuição que normalmente se encontram muito longe da implantação do empreendimento/atividade, mas que são efetivamente impactadas.

Outro exemplo é o sistema viário, que pode receber um volume capaz de alterar o nível de serviço de vias distantes do empreendimento que, aparentemente, não possuem nenhum tipo de relação com o objeto da análise.

Com relação à abrangência temporal, nas pesquisas e nos trabalhos foram identificadas quatro instâncias de alcance temporal dos impactos: 1) temporário, 2) cíclico, 3) sazonal e 4) permanente. Vê-se ainda que a dimensão temporal deve levar em conta quatro marcos de tempo do empreendimento: 1) situação atual, que é a situação existente antes da ação proposta; 2) situação obra, que é a situação que ocorrerá durante o período de obras do empreendimento; 3 ) situação esperada, que corresponde ao que foi planejado e avaliado com as alterações promovidas pela implantação do empreendimento; e 4) situação ao longo do tempo, que se refere à dinâmica dos impactos que ocorrerão durante o ciclo de vida do empreendimento, conforme ilustrado na Figura 1.

\section{Figura 1 - Abrangência temporal dos impactos}

Níveis de análise - abrangência temporal

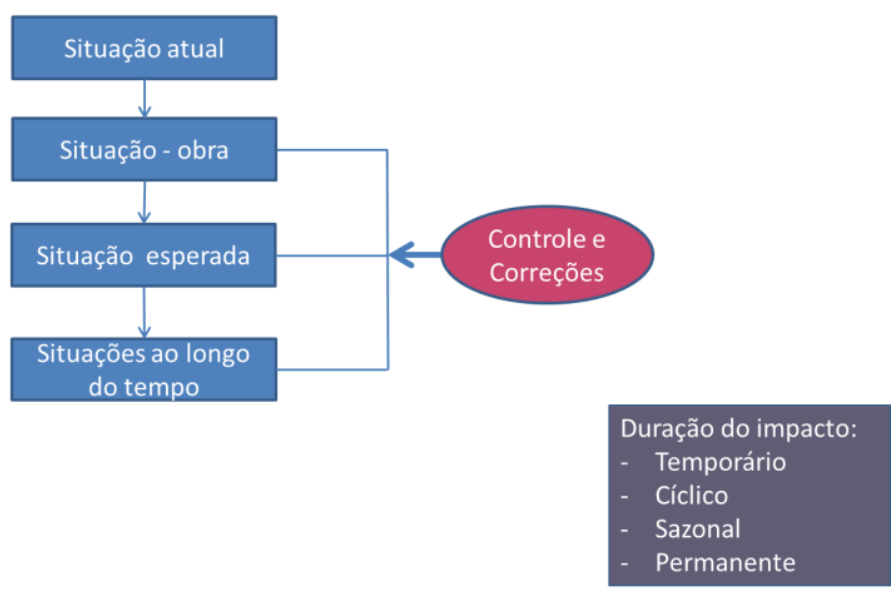

32 Barreiros, M. A. F.; Abiko, A. K. 
Baseado no enfoque sistêmico, foi proposta a decomposição dos itens constantes na itemização apresentada pelo Estatuto da Cidade em subitens que possuem funções relacionais entre si. A Tabela 5 apresenta uma matriz relacional do item "adensamento demográfico" com o incremento de demanda de serviços públicos e suas relações com a abrangência espacial, caráter do impacto, se positivo, nulo ou negativo, se o impacto é do tipo direto ou indireto, intensidade ou severidade do impacto, sua dimensão temporal e sazonalidade, conforme se verifica na matriz da Tabela 5. Notese que nessa tabela o alcance temporal dos impactos ainda era caracterizado como de reflexos imediatos, de médio e de longo prazo, e a questão da sazonalidade era analisada separadamente. Isso foi aperfeiçoado posteriormente.

Buscou-se ainda identificar as inter-relações existentes entre os itens avaliados entre si mediante aplicação de indicadores binários. O resultado indicou que o uso e ocupação do solo era o item com maior número de inter-relações com os outros aspectos estudados, como demonstra a Tabela 6. Por exemplo, a itemização, constante em EIV desenvolvido para uma unidade de lanchonete de rede de "fast-food", não corresponde diretamente aos itens propostos pelo Estatuto da Cidade, pois se buscava estabelecer uma ordem de grandeza entre impactos já anteriormente elencados e o item iluminação e ventilação já havia sido caracterizado como de impacto nulo, não possuindo inter-relações com os demais itens avaliados.

Ainda em 2013, o método foi novamente aperfeiçoado com a utilização de mais uma matriz derivada da matriz de Leopold, que foi a matriz de magnitude dos itens impactados durante a obra e o funcionamento do empreendimento analisado, conforme se verifica na Tabela 7 .

Para diminuir ainda mais o grau de subjetividade das avaliações, que é uma característica nos processos de avaliação (LAWRENCE, 2007b, p. 766), as avaliações passaram a ser feitas por três técnicos de forma independente, sem comunicação entre eles. Isso permitiu uma avaliação com menor grau de subjetividade.

Ambas as matrizes derivadas da matriz de Leopold passaram a utilizar uma escala de avaliação decimal e completavam as matrizes de avaliação de escala binária.

A utilização das matrizes de magnitude e importância e de inter-relações foi muito útil para apontar, com maior clareza, quais seriam os impactos mais importantes dos empreendimentos estudados e em que fase de implantação ou de operação estes ocorreriam.

Tabela 5 - Caracterização de impactos quanto a abrangência, caráter, tipo, severidade, temporariedade e sazonalidade sobre o subitem adensamento demográfico

\begin{tabular}{|c|c|c|c|c|c|c|c|c|c|c|c|c|c|c|c|}
\hline \multirow{2}{*}{$\begin{array}{l}\text { Item analisado } \\
\text { Adensamento demográfico }\end{array}$} & \multicolumn{3}{|c|}{ Abrangência Espacial } & \multicolumn{3}{|c|}{ Caráter } & \multicolumn{2}{|c|}{ Tipo } & \multicolumn{3}{|c|}{ Intensidade } & \multicolumn{4}{|c|}{ Duração } \\
\hline & AVI & AID & All & Positivo & Nulo & Negativo & Direto & Indireto & Baixa & Média & Alta & Temp. & Ciclíco & Sazonal & Permanente \\
\hline Abastecimento de água & $\mathrm{x}$ & $\mathrm{x}$ & $\mathrm{x}$ & & & $\mathrm{x}$ & $\mathrm{x}$ & & & $\mathrm{x}$ & & & & & $\mathrm{x}$ \\
\hline Tratamento de esgoto & $\mathrm{x}$ & $\mathrm{x}$ & $\mathrm{x}$ & & & $\mathrm{x}$ & $\mathrm{x}$ & & & $\mathrm{x}$ & & & & & $\mathrm{x}$ \\
\hline Energia elétrica & $\mathrm{x}$ & & & & & $\mathrm{x}$ & & $\mathrm{x}$ & & $\mathrm{x}$ & & & & & $\mathrm{x}$ \\
\hline Gás & $\mathrm{x}$ & & & & & $\mathrm{x}$ & & $\mathrm{x}$ & $\mathrm{x}$ & & & & & & $\mathrm{x}$ \\
\hline Drenagem & $x$ & & & & & $\mathrm{x}$ & $\mathrm{x}$ & & & & $x$ & & $\mathrm{x}$ & $x$ & \\
\hline Iluminação pública & $\mathrm{x}$ & & & $\mathrm{x}$ & & & $\mathrm{x}$ & & $\mathrm{x}$ & & & & & & $\mathrm{x}$ \\
\hline Sistema viário & $\mathrm{x}$ & $\mathrm{x}$ & & & & $\mathrm{x}$ & $\mathrm{x}$ & & & & $\mathrm{x}$ & & $\mathrm{x}$ & & $\mathrm{x}$ \\
\hline Tráfego & $\mathrm{x}$ & $\mathrm{x}$ & & & & $\mathrm{x}$ & $\mathrm{x}$ & & & & $\mathrm{x}$ & & $x$ & & $\mathrm{x}$ \\
\hline Sistema de transporte & & $\mathrm{x}$ & $\mathrm{x}$ & & & $\mathrm{x}$ & $\mathrm{x}$ & & & & $\mathrm{x}$ & & & & $\mathrm{x}$ \\
\hline Equipamentos de saúde & & & $\mathrm{x}$ & & $x$ & & & $\mathrm{x}$ & $\mathrm{x}$ & & & & & & $x$ \\
\hline Equipamentos de educação & $\mathrm{x}$ & $\mathrm{x}$ & $\mathrm{x}$ & & $x$ & & & $x$ & $x$ & & & & & $\mathrm{x}$ & \\
\hline Equipamentos de segurança & $x$ & $x$ & & $\mathrm{x}$ & & & $\mathrm{x}$ & & & $\mathrm{x}$ & & & & & $x$ \\
\hline Equipamentos de cultura e lazer & & & $\mathrm{x}$ & $\mathrm{x}$ & & & $\mathrm{x}$ & & & $\mathrm{x}$ & & & & & $\mathrm{x}$ \\
\hline Ativides econômicas & & $x$ & $\mathrm{x}$ & $\mathrm{x}$ & & & $\mathrm{x}$ & & & & $\mathrm{x}$ & & & & $\mathrm{x}$ \\
\hline Criação de empregos & & & $\mathrm{x}$ & $\mathrm{x}$ & & & $\mathrm{x}$ & & & & $x$ & & $\mathrm{x}$ & & \\
\hline Meio ambiente & $\mathrm{x}$ & $\mathrm{x}$ & & & & $\mathrm{x}$ & $\mathrm{x}$ & & & & $x$ & & & & $\mathrm{x}$ \\
\hline Microclima & $\mathrm{x}$ & & & & & $\mathrm{x}$ & $\mathrm{x}$ & & & $\mathrm{x}$ & & & & & $\mathrm{x}$ \\
\hline Paisagem & $\mathrm{x}$ & & & $\mathrm{x}$ & & & $\mathrm{x}$ & & & $\mathrm{x}$ & & & & & $\mathrm{x}$ \\
\hline Poluição atmosferíca & $\mathrm{x}$ & & & & & $\mathrm{x}$ & $\mathrm{x}$ & & $\mathrm{x}$ & & & & & & $\mathrm{x}$ \\
\hline Poluição sonora & $\mathrm{x}$ & & & & & $\mathrm{x}$ & $\mathrm{x}$ & & $\mathrm{x}$ & & & $\mathrm{x}$ & & & \\
\hline Produção de resíduos sólidos & & & $\mathrm{x}$ & & & $\mathrm{x}$ & $\mathrm{x}$ & & & $\mathrm{x}$ & & & & & $\mathrm{x}$ \\
\hline Obras & $\mathrm{x}$ & $\mathrm{x}$ & $\mathrm{x}$ & & & $\mathrm{x}$ & $\mathrm{x}$ & & & & $\mathrm{x}$ & $\mathrm{x}$ & & & \\
\hline
\end{tabular}

Fonte: EIV para centro de compras, desenvolvido pelo autor em 2014. 
Tabela 6 - Matriz de inter-relações

\begin{tabular}{|c|c|c|c|c|c|c|c|c|c|c|c|c|c|c|}
\hline MATRIZ DE INTER-RELAÇÕES & 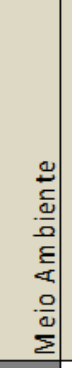 & 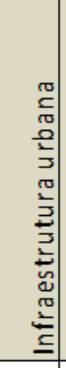 & 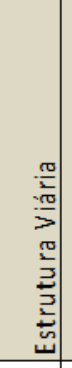 & $\begin{array}{c} \\
\varepsilon \\
0 \\
0 \\
\approx \\
\frac{.}{\pi} \\
0 \\
0\end{array}$ & 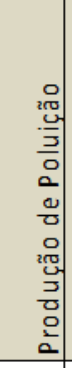 & 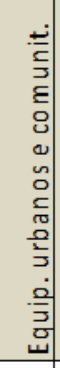 & 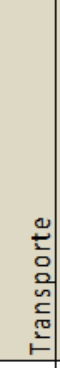 & 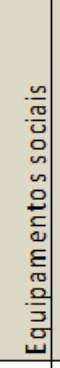 & 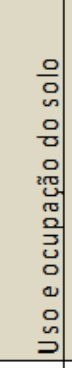 & 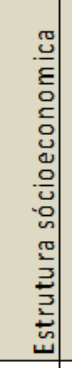 & 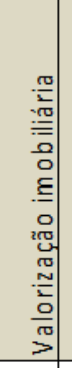 & $\begin{array}{l}n \\
0 \\
0 \\
0 \\
0 \\
\text { है } \\
0 \\
0 \\
\vdots \\
\vdots \\
0 \\
0\end{array}$ & 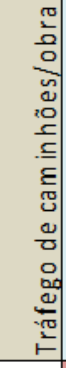 & 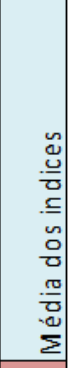 \\
\hline Meio Ambiente & & 0 & 0 & -1 & -1 & 0 & -1 & 0 & 0 & 0 & 0 & 0 & -1 & $-0,33$ \\
\hline Infraestrutura urbana & 0 & & -1 & 0,5 & 0 & 0 & -1 & 0 & 1 & 1 & 1 & 0 & $-0,5$ & 0,083 \\
\hline Estrutura viária & 0 & -1 & & 0 & 0 & 0 & -1 & 0 & 0 & 1 & 1 & 0 & -1 & $-0,08$ \\
\hline Paisagem & 1 & 0,5 & 0 & & 0 & 0 & 0 & 0 & 1 & 0,5 & 1 & 0 & 0 & 0,333 \\
\hline Poluição & -1 & 0 & 0 & 0 & & 0 & -1 & 0 & 0 & 0 & 0 & 0 & -1 & $-0,25$ \\
\hline Equipamentos urbanos e comunitários & 0 & 0 & 0 & 0 & 0 & & 0 & 0 & 0 & 0 & 0 & 0 & 0 & 0 \\
\hline Transporte & -1 & -1 & -1 & 0 & -1 & 0 & & 0 & 1 & 1 & 1 & 0 & -1 & $-0,17$ \\
\hline Equipamentos sociais & 0 & 0 & 0 & 0 & 0 & 0 & 0 & & 0 & 0 & 0 & 0 & 0 & 0 \\
\hline Uso e ocupação do solo & 0 & 1 & -1 & 1 & $-0,5$ & 0 & -1 & 0 & & 1 & 1 & 0 & 0 & 0,125 \\
\hline Estrutura socio-econômica & 0 & 0 & 1 & 0 & $-0,5$ & 0 & 0 & 0 & 1 & & 1 & 0 & 0 & 0,208 \\
\hline Valorização Imobiliária & 0 & 1 & 1 & 0 & 0 & 1 & 1 & 0 & 1 & 1 & & 0 & 0 & 0,5 \\
\hline Incremento no tráfego & $-0,5$ & -1 & -1 & -1 & -1 & 0 & 0 & 0 & $-0,5$ & 0 & $-0,5$ & & -1 & $-0,54$ \\
\hline Trafego de caminhões/obra & -1 & -1 & -1 & -1 & -1 & 0 & 0 & 0 & 0 & 0 & 0 & 0 & & $-0,42$ \\
\hline
\end{tabular}

Fonte: EIV de lanchonete, desenvolvido pelo autor em 2013.

Tabela 7 - Matriz de magnitude de impacto

\begin{tabular}{|c|c|c|c|c|c|c|c|}
\hline Item analisado & A & $\mathrm{B}$ & C & $\mathrm{D}$ & $\mathrm{E}$ & $\mathrm{F}$ & Pontuação do item \\
\hline Circulação de pessoas & 8 & 5 & 8 & 5 & 8 & 8 & 42 \\
\hline Tráfego local & 10 & 10 & 10 & 10 & 5 & 8 & 53 \\
\hline Sistema de transporte & 5 & 5 & 5 & 5 & 2 & 5 & 27 \\
\hline Abastecimento de água & 0 & 0 & 0 & 0 & 2 & 3 & 5 \\
\hline Tratamento de esgoto & 0 & 0 & 0 & 0 & 2 & 3 & 5 \\
\hline Energia elétrica & 0 & 0 & 0 & 3 & 2 & 5 & 10 \\
\hline Gás & 0 & 0 & 0 & 0 & 0 & 2 & 2 \\
\hline Drenagem & 5 & 5 & 5 & 0 & 0 & 4 & 19 \\
\hline Iluminação pública & 2 & 2 & 2 & 2 & 2 & 2 & 12 \\
\hline Sistema viário & 8 & 10 & 8 & 2 & 7 & 8 & 43 \\
\hline Equipamentos de saúde & 0 & 0 & 0 & 0 & 0 & 2 & 2 \\
\hline Equipamentos de educação & 0 & 0 & 0 & 0 & 0 & 4 & 4 \\
\hline Equipamentos de segurança & 0 & 0 & 0 & 0 & 0 & 4 & 4 \\
\hline Equipamentos de cultura e lazer & 0 & 0 & 0 & 0 & 0 & 4 & 4 \\
\hline Ativides econômicas & 2 & 2 & 2 & 5 & 8 & 10 & 29 \\
\hline Criação de empregos & 5 & 5 & 5 & 8 & 8 & 10 & 41 \\
\hline Fauna local & 5 & 0 & 0 & 0 & 0 & 0 & 5 \\
\hline Flora local & 5 & 0 & 0 & 0 & 0 & 0 & 5 \\
\hline Microclima & 2 & 2 & 2 & 2 & 2 & 5 & 15 \\
\hline Ventilação e iluminação & 0 & 0 & 5 & 5 & 0 & 5 & 15 \\
\hline Paisagem & 5 & 5 & 5 & 5 & 7 & 10 & 37 \\
\hline Poluição atmosferíca & 8 & 5 & 5 & 2 & 2 & 3 & 25 \\
\hline Poluição sonora & 10 & 10 & 8 & 8 & 7 & 3 & 46 \\
\hline Produção de resíduos sólidos & 10 & 8 & 8 & 6 & 7 & 5 & 44 \\
\hline Pontuação da atividade & 90 & 74 & 78 & 68 & 71 & 113 & \\
\hline
\end{tabular}

A- Terraplenagem; B- Fundações; Estruturas; C- Vedações e acabamentos; D- Instalação de equipamentos; E- finalização das obras; F- Funcionamentc

Fonte: EIV de hospital, desenvolvido pelo autor em 2014.

34 Barreiros, M. A. F.; Abiko, A. K. 
O passo seguinte no desenvolvimento do método de avaliação de impactos de vizinhança por meio de matrizes numéricas foi estabelecer uma relação de grandeza dos impactos entre os itens avaliados através do método pairwise comparison.

Foi utilizada a comparação por pares para uma avaliação inicial, a fïm de estabelecer uma hierarquia de importância dos impactos e dos itens impactados. Para aprimorar essa avaliação levando em conta as inter-relações entre os impactos, buscou-se verificar as possibilidades da utilização do método AHP desenvolvido por Saaty (1991).

A comparação por pares foi utilizada como mais um instrumento de análise para complementar os resultados obtidos nas outras matrizes. Saaty (1991) propõe uma avaliação baseada na comparação entre pares e utiliza uma escala de valores baseadas nos critérios apresentados na Tabela 8 .

Utilizando a avaliação por pares da matriz recíproca do método de Saaty e calculando-se o autovalor (v) da matriz e o autovalor normalizado obtém-se a hierarquia do grau de incomodidade dos impactos avaliados. No caso ilustrado na Tabela 9, em que a matriz já incorpora o cálculo do autovalor e o autovalor normalizado, vê-se que os impactos no tráfego e transporte foram avaliados como os mais importantes no EIV desenvolvido. A utilização do método AHP permitiu uma visão mais clara da hierarquização dos itens de avaliação de impactos para cada empreendimento.

\section{Tabela 8 - Índices do método AHP}

\begin{tabular}{r|l}
\multicolumn{2}{l}{ Utilização de indices definidos SAATY (1980) } \\
\multicolumn{1}{|l}{ Índice } & \\
\hline 1 & Igual importancia entre as variáveis \\
\hline 3 & Importância pequena de uma sobre a outra \\
\hline 5 & Importância grande ou essencial \\
\hline 7 & Importância muito grande ou demonstrada \\
\hline 9 & Importância absoluta de uma sobre a outra \\
\hline $2,4,6,8$ & Valores intermediários \\
\hline
\end{tabular}

Fonte: Saaty (1991).

Tabela 9 - Comparação por pares

\begin{tabular}{|c|c|c|c|c|c|c|c|c|c|c|c|c|c|}
\hline Pairwise Comparison & 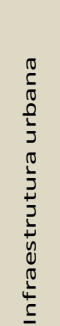 & 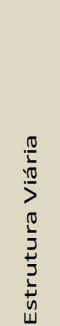 & $\begin{array}{l}\varepsilon \\
\frac{\varepsilon}{0} \\
\frac{0}{0} \\
\frac{0}{\pi} \\
0 \\
0\end{array}$ & 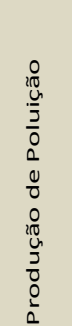 & 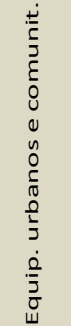 & $\begin{array}{l}0 \\
t \\
0 \\
0 \\
\frac{0}{n} \\
\tilde{c} \\
\tilde{L}\end{array}$ & 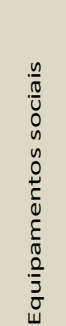 & $\begin{array}{l}0 \\
\frac{0}{0} \\
n \\
0 \\
0 \\
0 \\
0 \\
0 \\
0 \\
0 \\
0 \\
3 \\
0 \\
0 \\
0 \\
0 \\
0 \\
0\end{array}$ & 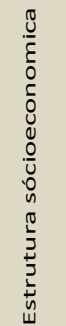 & 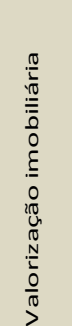 & 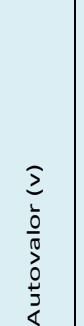 & 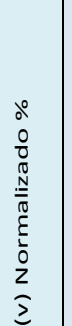 & $\begin{array}{l}\frac{\pi}{J} \\
\frac{\sigma}{\sigma} \\
\frac{\pi}{0} \\
\stackrel{\bar{I}}{I}\end{array}$ \\
\hline Infraestrutura urbana & & 1 & 5 & 7 & 1 & 1 & 1 & 1 & 1 & 5 & 1,78 & 13,694 & 3 \\
\hline Estrutura viária & 1 & & 3 & 7 & 1 & 1 & 1 & 3 & 3 & 5 & 2,14 & 16,516 & 2 \\
\hline Paisagem & $1 / 3$ & $1 / 5$ & & 9 & 1 & 1 & 1 & 3 & 1 & 3 & 1,21 & 9,304 & 6 \\
\hline Poluição & $1 / 7$ & $1 / 7$ & 1 & & $1 / 7$ & 1 & 1 & 1 & 1 & 1 & 0,52 & 4,033 & 9 \\
\hline Equipamentos urbanos e comunitários & 1 & 1 & 1 & 7 & & 1 & 1 & 1 & 1 & 7 & 1,54 & 11,888 & 4 \\
\hline Tráfego e Transporte & 1 & 1 & 3 & 5 & 3 & & 3 & 1 & 3 & 5 & 2,33 & 17,975 & 1 \\
\hline Equipamentos sociais & 1 & 1 & 3 & 3 & 1 & $1 / 3$ & & $1 / 3$ & 1 & 3 & 1,13 & 8,716 & 7 \\
\hline Uso ecupação do solo & 1 & $1 / 3$ & $1 / 3$ & 1 & 1 & 1 & 3 & & 5 & 7 & 1,31 & 10,135 & 5 \\
\hline Estrutura socio-econômica & 1 & $1 / 3$ & 1 & 1 & 1 & $1 / 3$ & 1 & $1 / 5$ & & 3 & 0,74 & 5,710 & 8 \\
\hline \multirow[t]{2}{*}{ Valorização Imobiliária } & $1 / 5$ & $1 / 5$ & $1 / 3$ & 1 & $1 / 7$ & $1 / 5$ & $1 / 3$ & $1 / 7$ & $1 / 3$ & & 0,26 & 2,030 & 10 \\
\hline & 6,6 & 5,2 & 17,67 & 41,00 & 9,29 & 6,8 & 12,3 & 10,68 & 16,33 & 39,00 & 12,96299 & 100 & \\
\hline
\end{tabular}

Fonte: EIV de um hospital, desenvolvido pelo autor em 2014. 
A utilização das matrizes do método AHP, de inter-relações e de caracterização de impactos, com a decomposição dos itens indicados pelo Estatuto da Cidade em subitens, foi somada ao uso das matrizes de magnitude de impactos no tempo e com a matriz de magnitude e importância derivada da matriz de Leopold. A utilização dessas matrizes foi importante para as avaliações, permitindo uma leitura mais objetiva dos impactos. Ressalta-se que a elaboração das matrizes, sempre feita por três técnicos de forma independente, diminuiu a possibilidade de avaliações baseadas em apenas um julgamento subjetivo. Não obstante, é preciso considerar que a abordagem utilizada nos trabalhos, caracterizada como technical approach por Lawrence (2007a), possui limitações e deve ser contextualizada em um sistema de avaliações que leve em conta as outras abordagens descritas pelo citado autor, a saber: collaborative approach, reasoned argumentation approach e composite approach. A experiência empírica indica que as matrizes numéricas não substituem os estudos e análises quantitativos e qualitativos e as abordagens colaborativa, da argumentação fundamentada e a determinação de significância composta, descritas por Lawrence (2007a), mas permitem, de forma suplementar, fazer avaliações comparativas tanto entre os impactos como entre as alternativas de projeto.

\section{Conclusões}

Esta pesquisa foi dividida em quatro etapas. Com relação à primeira etapa, verificou-se que um dos grandes problemas existentes na avaliação de impactos é o alto grau de subjetividade existente na mensuração e nas análises dos impactos. As pesquisas diretas de Moreira (1997), de Lollo e Röhm (2005, 2006), de Marques (2010) indicam que a elaboração dos estudos de impacto de vizinhança precisa ser aperfeiçoada. Ainda é pequena a produção acadêmica sobre o tema, inexistindo trabalhos específicos que relacionem a avaliação dos impactos de vizinhança com matrizes apoiadas no método AHP.

Com relação à segunda etapa das pesquisas concluiu-se que, embora estabelecido em 2001, o EIV ainda não é um instrumento urbanístico adotado pela maioria dos municípios. Tomando a região metropolitana de São Paulo como objeto de pesquisa constatou-se que apenas $28,2 \%$ dos municípios regulamentaram o EIV e o aplicam regularmente.

A terceira etapa das pesquisas demonstrou que o uso de matrizes numéricas ainda é praticamente inexistente nas avaliações de impactos de vizinhança, como comprova a Tabela 2 . Um dos objetivos dessa pesquisa era demonstrar o que já foi observado informalmente em todos os municípios da RMSP, que é a inexistência de avaliações dos impactos de vizinhança desenvolvidas por meio de matrizes numéricas, não obstante seu uso ser recomendado, há mais de duas décadas, pelas publicações de Leopold (1971) e Saaty (1991) e pela disseminação das matrizes de interação em EIA, conforme afirmam BojórquezTapia, Ezcurra e Garcia (1998)

A quarta etapa das pesquisas demonstra que a utilização de matrizes numéricas e do método AHP pode ser útil como ferramenta auxiliar na avaliação de impactos de vizinhança, integrando o EIV, assim como já faz parte das análises de EIA.

Constatou-se também que a inserção do enfoque sistêmico dentro da abordagem de Churchman permite novos aperfeiçoamentos dos métodos de identificação, qualificação e quantificação de impactos derivados da matriz de Leopold e suas sucedâneas. A utilização de índices derivados da matriz de Leopold e das outras matrizes apresentadas neste trabalho pode dar apoio metodológico aos EIVs, o que contribui para reduzir a subjetividade das avaliações. Há espaço para o aperfeiçoamento de métodos para a determinação da significância de impactos (LAWRENCE, 2007b). Finalmente, o sistema de matrizes é um instrumento importante para a avaliação de impactos de vizinhança, e deve ser aperfeiçoado e inserido contextualmente e em conjunto com outras abordagens de avaliação de impactos.

\section{Referências}

ABIKO, A.; BARREIROS, M. A.F. Urban

Sustainability and Neighborhood Impact

Assessment in Brazil. In: INTERNATIONAL

COUNCIL FOR RESEARCH AND

INTERVENTION IN BUILDING

CONSTRUCTION. Rotherdam, 2014.

Proceedings... Rotherdam, 2014.

ALMEIDA, C.; BRUNA, G. C.; SIMÕES

JUNIOR, J. G. Gestão Ambiental Urbana e o

Estudo de Impacto de Vizinhança. Cadernos de

Pós-Graduação em Arquitetura e Urbanismo,

São Paulo, v. 4, n.1, p 101-112, 2004.

BERTALANFFY, L. V. Teoria Geral dos

Sistemas. 3. ed. Petrópolis: Vozes, 1977.

BOJÓRQUEZ-TAPIA, L. A.; EZCURRA, E; GARCÍA, O. Appraisal of Environmental Impacts and Mitigation Measures Through Mathematical Matrices. Journal of Environmental

Management, v. 53, n. 1, p. 91-99, 1998. 
BRASIL. Lei ${ }^{\circ}$ 10.257, de 10 de julho de 2001, que regulamenta os artigos. 182 e 183 da Constituição Federal, estabelece diretrizes gerais da política urbana e dá outras providências. Diário Oficial da União, Brasília, DF, 11 de julho de 2001.

BRASIL. Lei ${ }^{\circ}$ 6.766, de 19 de dezembro de 1979, que dispõe sobre o parcelamento do solo urbano e dá outras providências. Legislação Básica de Interesse Metropolitano. São Paulo: Emplasa, 1985.

BRASIL. Lei ${ }^{\circ} 6.938$ de 31 de agosto de 1981, que institui a Politica Nacional de Meio Ambiente, seus fins e mecanismos de formulação e aplicação, e dá outras providências. Diário Oficial da União, Brasília, DF, 01 de setembro de 1981.

CANTER, L. W. et al. Environmental Impact Assessment. CRC Press, 1996. Disponível em: <ftp://www.energia.bme.hu/pub/hullgazd/Environ mental\%20Engineers'\%20Handbook/Ch02.pdf> Acesso em: 10 jul. 2015.

CHAMIÉ, P. M. B. Contexto Histórico, sob o Enfoque Urbanístico, da Formulação e Legalização do Estudo de Impacto de Vizinhança. São Paulo, 2010. Dissertação (Mestrado em Arquitetura e Urbanismo) - Escola de Engenharia, Universidade de São Paulo, São Paulo, 2010.

\section{CHURCHMAN, C. W. Introdução à Teoria dos}

Sistemas. 2. ed. Petrópolis: Vozes, 1971.

CYMBALISTA, R. Estudo de Impacto de Vizinhança. Dicas Polis, v. 192, p. 12-15, 2001.

\section{CONSELHO NACIONAL DO MEIO}

AMBIENTE. Resolução no 01, de 23 de janeiro de 1986, que dispõe sobre critérios básicos e diretrizes gerais para o Relatório de Impacto Ambiental - RIMA. Disponível em: <http://www.mma.gov.br/port/conama/legiabre.cf m?codlegi=23>. Acesso em: 14 maio 2013.

DE CAMPOS, B. A. Diretrizes Para Análise de Impacto em Meio Urbano Baseadas em Estudo de Impacto de Vizinhança (EIV). Florianópolis, 2005. Tese (Doutorado em Engenharia de Produção) - Programa de Pós-Graduação em Engenharia de Produção, Universidade Federal de Santa Catarina, Florianópolis, 2005.

\section{EMPRESA PAULISTA DE PLANEJAMENTO} METROPOLITANO SA. Indicadores. Disponível em:

<http://www.emplasa.sp.gov.br/Emplasa/Indicador es/gsp.asp>. Acesso em: 10 jul. 2015.
GLASSON, J. et al. Introduction to

Environmental Impact Assessment: principles and procedures, process, practice and prospects. $2^{\text {nd }}$. ed. London: UCL, 1999.

\section{INSTITUTO BRASILEIRO DE GEOGRAFIA E} ESTATÍSTICA. Censo Demográfico 2010

Resultados Gerais da Amosta. IBGE, 2012. Disponível em: <http://www.censo2010.ibge.gov.br/sinopse/index. php?dados=8>. Acesso em: 2 set. 2014.

LAWRENCE, D. P. Impact Significance Determination: back to basics. Environmental Impact Assessment Review, v. 27, n. 8, p. 755769, $2007 b$.

LAWRENCE, D. P. Impact Significance Determination: designing an approach. Environmental Impact Assessment Review, v. 27, n. 8, p. 730-754, 2007a.

\section{LEOPOLD, L. B. A Procedure for Evaluating}

Environmental Impact. Washington, 1971. Geological Survey Circular n 645 . US Department of the Interior.

LOLLO, J. A. de; RÖHM, S. A. Aspectos Negligenciados em Estudos de Impacto de Vizinhança. Estudos Geográficos, Rio Claro, v. 3, n. 2, p. :31-45, dez. 2005.

LOLLO, J. A. de; RÖHM, S. A. Proposta de Matriz Para Levantamento e Avaliação de Impactos de Vizinhança. Holos Environment, v. 5, n. 2, p. 169-183, 2006.

\section{MARQUES, J. S. Estudo de Impacto de} Vizinhança: uma análise crítica feita por meio dos relatórios de impacto de vizinhança apresentados no D.F. Brasília, 2010. Dissertação (Mestrado em Engenharia Civil) - Escola de Engenharia, Universidade Federal de Brasília, Brasília, 2010.

MOLINA JÚNIOR, V. E. Estudo de Impacto de Vizinhança: avaliação de impactos gerados por supermercados em cidades de portes diferentes. São Carlos, 2011. Tese (Doutorado em Engenharia Urbana). Universidade Federal de São Carlos, São Carlos, 2011.

MOREIRA, A. C. M. L. Mega-Projetos \& Ambiente Urbano: uma metodologia para elaboração de relatório de impacto de vizinhança. 1997. Tese (Doutorado em Engenharia Civil) Faculdade de Arquitetura e Urbanismo, Universidade de São Paulo, São Paulo, 1997.

MOTA, S.; AQUINO, M. D. Proposta de Uma Matriz Para Avaliação de Impactos Ambientais. In: SIMPÓSIO ÍTALO BRASILEIRO DE ENGENHARIA SANITÁRIA E AMBIENTAL, 6., Rio de Janeiro, 2002. Anais... Rio de Janeiro: ABES, 2002. 
PEREIRA, G. G. Modelo de Atração de Automóveis por Shopping Center. São Paulo, 2011. Companhia de Engenharia de Tráfego. Boletim Técnico 46.

ROCCO, R. Estudo de Impacto de Vizinhança: instrumentode garantia do direito às cidades sustentáveis. Rio de Janeiro: Lumen Juris, 2006.

SAATY, T. L. Método de Análise Hierárquica. São Paulo: McGraw-Hill, 1991.

SANTOS, M. A Urbanização Brasileira. São Paulo: Edusp, 2005.

SÃO PAULO (Estado). Lei n ${ }^{\circ} 1.172$ de 17, de novembro de 1976, que delimita as áreas de proteção aos mananciais, cursos e reservatórios de água e dá outras providências. Legislação Básica de Interesse Metropolitano. São Paulo: Emplasa, 1985.

SÃO PAULO (Estado). Lei n ${ }^{\circ} 1.817$, de 27 de outubro de 1978, que estabelece os objetivos e as diretrizes para o desenvolvimento industrial metropolitano e disciplina o zoneamento industrial e dá providências correlatas. Legislação Básica de Interesse Metropolitano. São Paulo: Emplasa, 1985.

SÃO PAULO (Município). Lei no 11.228, de 25 de junho de 1992, que dispõe sobre as regras gerais e específicas a serem obedecidas no projeto, licenciamento, execução, manutenção e utilização de obras e edificações, dentro dos limites dos imóveis. Disponível em:

<http://www.prefeitura.sp.gov.br/cidade/secretaria s/subprefeituras/upload/pinheiros/arquivos/lei11_2 28.pdf>. Acesso em: 23 nov. 2014.
SÃO PAULO (Município). Lei n. ${ }^{\circ}$ 7.805, de $1^{\circ}$ de novembro de 1972 , que dispõe sobre o parcelamento uso e ocupacao-do-solo-domunicipio-e-da-outras-providencias. In: Lei Orgânica do Município de São Paulo, de 04 de abril de 1990. Disponível em:

<http://www.prefeitura.sp.gov.br/cidade/secretaria s/upload/educacao/cme/LOM.pdf $>$. Acesso em: 18 nov. 2014.

SÃO PAULO (Município). Lei n. ${ }^{\circ} \mathbf{1 0 . 5 0 6}$ de 04 de maio de 1988, que dispõe sobre obras e serviços a serem executados no sistema viário em decorrência da implantação de empreendimentos particulares e dá outras providências.

Disponível em:

<https://leismunicipais.com.br/a/sp/s/sao-paulo/leiordinaria/1988/1050/10506/lei-ordinaria-n-105061988-dispoe-sobre-obras-e-servicos-a-seremexecutados-no-sistema-viario-em-decorrencia-daimplantacao-de-empreendimentos-particulares-eda-outras-providencias>. Acesso em: 30 abr. 2016.

SÃO PAULO. (Estado). Lei n ${ }^{\circ} 898$, de 18 de dezembro de 1975, que disciplina o uso do solo para a proteção dos mananciais e recursos hídricos de interesse da Região Metropolitana da Grande São Paulo. Legislação Básica de Interesse Metropolitano. Emplasa, São Paulo, 1985.

SHEPARD, R. B. Quantifying Environmental Impact Assessments Using Fuzzy Logic. New York: Springer Science \& Business Media, 2005.

\section{Agradecimentos}

Nossos agradecimentos à Coordenadoria de Aperfeiçoamento de Pessoal de Nível Superior (Capes) pelo apoio.

Mário Antonio Ferreira Barreiros

Departamento de Engenharia de Construção Civil, Escola Politécnica | Universidade de São Paulo | Av. Prof. Almeida Prado, Travessa 2, n. 83 | São Paulo - SP - Brasil | CEP 05508-010 | Tel.: (11) 99102-2721 | E-mail: maba@usp.br

Alex Kenya Abiko

Departamento de Engenharia de Construção Civil, Escola Politécnica | Universidade de São Paulo | Tel.: (11) 3091-5449 |

E-mail: alex.abiko@poli.usp.br

Revista Ambiente Construído

Associação Nacional de Tecnologia do Ambiente Construído

Av. Osvaldo Aranha, $99-3^{\circ}$ andar, Centro

Porto Alegre - RS - Brasil CEP $90035-190$

Telefone: +55 (51) 3308-4084

Fax: +55 (51) 3308-4054

www.seer.ufrgs.br/ambienteconstruido

E-mail: ambienteconstruido@ufrgs.br

38 Barreiros, M. A. F.; Abiko, A. K. 